\title{
The Influence of Filler Type and Surface Area on the Hydration Rates of Calcium Aluminate Cement
}

\author{
Guillermo Puerta-Falla ( $\left(^{*}\right)$, Aditya Kumar $\left({ }^{+}\right)$, Lauren Gomez-Zamorano $\left({ }^{\ddagger},{ }^{\S}\right)$, Mathieu Bauchy $\left({ }^{* *}\right)$,

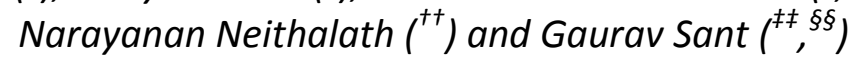

\section{Abstract}

The addition of finely pulverized materials such as limestone and quartz has been observed to increase the reaction rates of ordinary portland cement. This study describes the effects of mineral fillers including: limestone, dolomite and quartz on the hydration rates of calcium aluminate cements. By detailed analysis of isothermal calorimetry data and application of a phase boundary nucleation and growth model, it is shown that finely ground minerals enhance reaction rates in relation to: (1) their surface area, which increases with increasing proportion of CAC replacement by a fine mineral filler, and (2) the increase in the amount of water available for CAC hydration, i.e., dilution, that occurs as the CAC is replaced by a filler. Unlike in the case of OPC, CAC hydration rates, and enhancements therein in the presence of fillers are independent of the mineral type and are only a function of available surface area.

Keywords: limestone, dolomite, quartz, calcium aluminate cement, calorimetry.

\footnotetext{
"Laboratory for the Chemistry of Construction Materials $\left(\mathrm{LC}^{2}\right)$, Department of Civil and Environmental Engineering, University of California, Los Angeles, CA, USA, Email: gpuertafalla@ucla.edu

${ }^{+}$Laboratory for the Chemistry of Construction Materials $\left(\mathrm{LC}^{2}\right)$, Department of Civil and Environmental Engineering, University of California, Los Angeles, CA, USA, Email: adityaku@ucla.edu

${ }^{\ddagger}$ Laboratory for the Chemistry of Construction Materials $\left(\mathrm{LC}^{2}\right)$, Department of Civil and Environmental Engineering, University of California, Los Angeles, CA, USA

${ }^{\S}$ Programa Doctoral en Ingeniería de Materiales, Facultad de Ingeniería Mecánica y Eléctrica, Universidad Autónoma de Nuevo León, San Nicolás de los Garza, 66450, México, Email: lauren.gomezzm@uanl.edu.mx

** Laboratory for the Physics of Amorphous and Inorganic Solids (PARISlab), Department of Civil and Environmental Engineering, University of California, Los Angeles, CA, USA, Email: bauchy@ucla.edu

${ }^{++}$School of Sustainable Engineering and the Built Environment, Arizona State University, Tempe, AZ, USA, Email: naravanan.neithalath@asu.edu

${ }^{\ddagger \neq}$ Corresponding Author, Laboratory for the Chemistry of Construction Materials (LC $\left.{ }^{2}\right)$, Department of Civil and Environmental Engineering, University of California, Los Angeles, CA, USA, Email: gsant@ucla.edu

${ }^{\S}$ California Nanosystems Institute (CNSI), University of California, Los Angeles, CA, USA
} 


\subsection{Introduction and background}

21 Over the past several years, on account of its production related $\mathrm{CO}_{2}$ emissions, significant

22 efforts have been made to reduce the use of cement as the primary binding agent in concrete

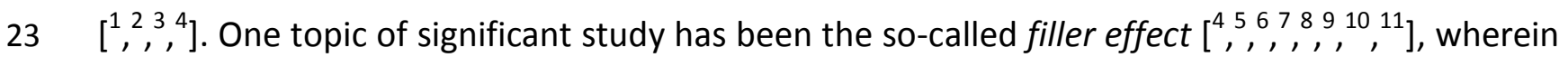

24 the replacement of OPC by a suitable filler (i.e., quartz, limestone, rutile) results in enhanced

25 reaction rates, allowing for reduction of the OPC content without compromising property gain

26 at early ages. The filler effect results from the enhanced nucleation of hydration products as

27 additional surface area is provided by fine filler agents. While a wide range of fillers have been

evaluated, in OPC, carbonate-based fillers (e.g., limestone, dolomite) have been noted to show

29 filler effects superior to other mineral agents on account of their superior surface properties, and chemical composition $\left[{ }^{6},{ }^{7}, 12,13,15\right]$.

32 Unlike OPC, calcium aluminate cements (CACs) consist dominantly of monocalcium aluminate $\left(\mathrm{CaO} \cdot \mathrm{Al}_{2} \mathrm{O}_{3}, \mathrm{CA}\right)$ and gehlenite $\left(2 \mathrm{CaO} \cdot \mathrm{Al}_{2} \mathrm{O}_{3} \cdot \mathrm{SiO}_{2}, \mathrm{C}_{2} \mathrm{AS}\right)^{* * *}\left[{ }^{16},{ }^{17},{ }^{18},{ }^{19}\right]$. In spite of several decades of use, the influence of fillers on CAC hydration has been lesser studied. Towards this end, the current study uses a combination of experiments and simulations to elucidate the effects of the filler content (i.e., $\mathrm{CAC}$ replacement level and w/c increase), filler type (i.e., $\mathrm{CaCO}_{3}, \mathrm{CaMg}\left(\mathrm{CO}_{3}\right)_{2}$ and $\alpha-\mathrm{SiO}_{2}$ ) and surface area (i.e., fineness of fillers) on CAC hydration kinetics. A boundary nucleation and growth model is used to explain the links between surface area, and mineral 39 type on hydration rates $\left[{ }^{7}, 9\right]$. The results suggest that CAC-based binders are far less sensitive to mineral filler type, than OPC-based systems.

\footnotetext{
"** Standard cement chemistry notation is used throughout this paper. As per this notation: $\mathrm{C}=\mathrm{CaO}, \mathrm{A}=\mathrm{Al}_{2} \mathrm{O}_{3}, \mathrm{~F}=\mathrm{Fe}_{2} \mathrm{O}_{3}, \mathrm{~S}=\mathrm{SiO}_{2}, \mathrm{~T}=\mathrm{TiO}_{2} \mathrm{CS}=\mathrm{CaSO} \cdot 2 \mathrm{H}_{2} \mathrm{O}$ and $\mathrm{H}=\mathrm{H}_{2} \mathrm{O}$.
} 


\subsection{Materials and Experimental Methods}

43 A commercially available grey calcium aluminate cement (CAC, referred to as CAC or cement

44 interchangeably, hereafter) Secar ${ }^{\circledR} 51$ produced by Kerneos Aluminate Technologies was used.

45 The oxide composition (Table 1) of the CAC was determined by X-ray florescence (XRF). The 46 mineralogical composition of the CAC as determined using Rietveld refinement of X-ray

47 diffraction (XRD) patterns is (by mass): $73.3 \% \mathrm{CA}, 18.1 \% \mathrm{C}_{2} \mathrm{AS}, 4.9 \% \mathrm{CT}$ with minor phases in the 48 form of $0.8 \% \mathrm{CaO}, 0.6 \% \mathrm{C}_{2} \mathrm{~F}, 1.5 \% \mathrm{C}_{3} \mathrm{FT}$ and $0.8 \% \mathrm{Fe}_{3} \mathrm{O}_{4}$. The limestone and quartz powders used 49 are commercially available size classified products produced by OMYA A.G. and U.S. Silica. The 50 dolomite used was produced by Blue Mountain Minerals. Oxide compositions of CAC and as 51 well as the main components for the fillers used can be found in Table 1.

Table 1: Oxide composition of CAC and Main components of fillers

\begin{tabular}{|c|c|c|c|c|}
\hline Sample & CAC: Secar 51 & Limestone & Dolomite & Quartz \\
\hline $\mathrm{SiO}_{2}$ & 4.71 & $\sim$ & 0.70 & 100.00 \\
\hline $\mathrm{Al}_{2} \mathbf{O}_{3}$ & 51.04 & $\sim$ & $\sim$ & $\sim$ \\
\hline $\mathrm{Fe}_{2} \mathbf{O}_{3}$ & 2.22 & $\sim$ & $\sim$ & $\sim$ \\
\hline $\mathrm{CaO}$ & 38.94 & $\sim$ & $\sim$ & $\sim$ \\
\hline $\mathrm{MgO}$ & 0.59 & $\sim$ & $\sim$ & $\sim$ \\
\hline $\mathrm{SO}_{3}$ & 0.00 & $\sim$ & $\sim$ & $\sim$ \\
\hline $\mathrm{Na}_{2} \mathbf{O}$ & 0.07 & $\sim$ & $\sim$ & $\sim$ \\
\hline $\mathrm{K}_{2} \mathrm{O}$ & 0.31 & $\sim$ & $\sim$ & $\sim$ \\
\hline $\mathrm{TiO}_{2}$ & 2.02 & $\sim$ & 19.30 & $\sim$ \\
\hline $\mathrm{P}_{2} \mathrm{O}_{5}$ & 0.11 & 100.00 & 80.00 & $\sim$ \\
\hline $\mathrm{CaCO}_{3}$ & $\sim$ & $\sim$ & 100.00 & 100.00 \\
\hline $\mathrm{CaMg}\left(\mathrm{CO}_{3}\right)_{2}$ & $\sim$ & 100.00 & & $\sim$ \\
\hline $\mathrm{Sum}$ & 100.00 & & $\sim$ & $\sim$ \\
\hline
\end{tabular}




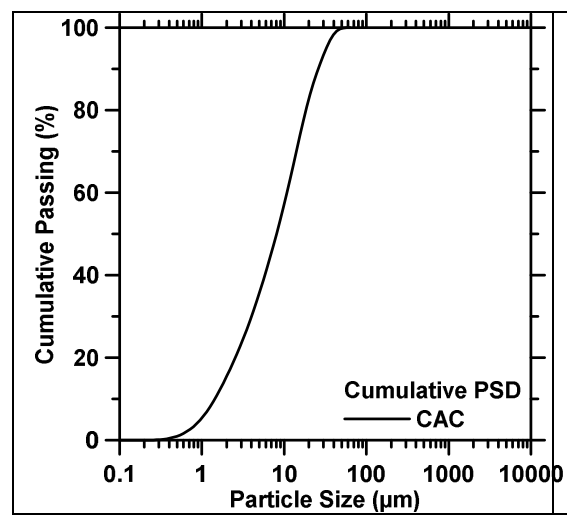

(a)

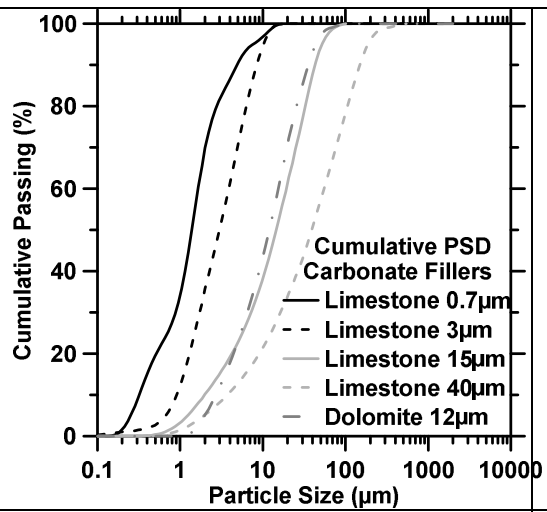

(b)

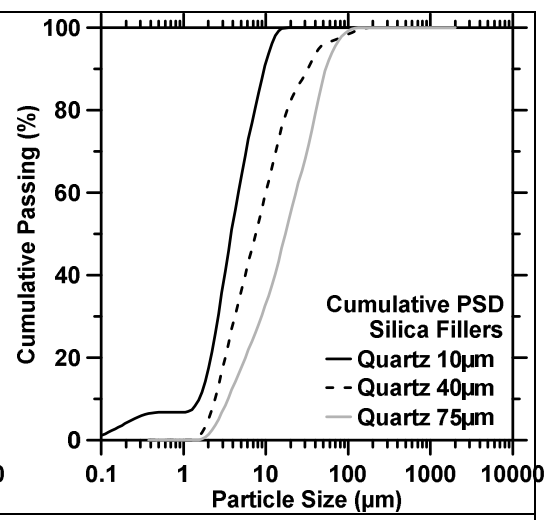

(c)

Figure 1: The particle size distributions (PSDs) of the: (a) calcium aluminate cement, (b) carbonate fillers (limestone, dolomite) and (c) quartz powders used in this study.

53

The particle size distributions (Figure 1) of the solids were measured using a Beckman Coulter static light-scattering (SLS) analyzer (LS13-320) using isopropanol/sonication for dispersing the powders to primary particles. This methodology allows the quantification of volume fractions of the particles corresponding to each size class ranging between $0.04 \mu \mathrm{m}$ and $2000 \mu \mathrm{m}$ using the Mie theory for analysis of light scattering data. Assuming spherical shape of the particles, the total surface area of the particles belonging to each size class is calculated and, ultimately, added to estimate the cumulative surface area per unit volume $\left(\mathrm{m}^{2} / \mathrm{m}^{3}\right)$ of the material. By factoring in the density of each powder (i.e. $3150,2700,2650$ and $2850 \mathrm{~kg} / \mathrm{m}^{3}$ for the CAC, limestone, quartz and dolomite respectively), the specific surface area is obtained in the units of $\mathrm{m}^{2} / \mathrm{kg}$. The uncertainty in the light scattering was determined to be $\approx 6 \%$ based on multiple measurements performed on six replicate samples. Given the irregular, angular nature of the particles considered, the spherical particle assumption results in an underestimation of the solid surface area by a factor of 1.6 -to- $1.8\left[^{20}\right]$ for typical pulverized powders. The median diameter $\left(d_{50}\right)$ and the specific surface area (SSA) for all materials are presented in Table 2. 
Table 2: The nominal specific surface area (SSA) and $d_{50}$ of the solids as calculated using the measured particle size distributions.

\begin{tabular}{|c|c|c|}
\hline Materials & SSA $\left(\mathbf{m}^{\mathbf{2}} / \mathbf{k g}\right)$ & Size $\left(\mathbf{d}_{\mathbf{5 0}}, \boldsymbol{\mu m}\right)$ \\
\hline Secar $\mathbf{5 1}$ & 504.85 & 8.15 \\
\hline Limestone $\mathbf{0 . 7} \boldsymbol{\mu m}$ & 2592.13 & 1.38 \\
\hline Limestone $\mathbf{3} \boldsymbol{\mu m}$ & 1353.29 & 2.92 \\
\hline Limestone $\mathbf{1 5} \boldsymbol{\mu m}$ & 399.29 & 14.26 \\
\hline Limestone $\mathbf{4 0} \boldsymbol{\mu m}$ & 228.62 & 39.78 \\
\hline Dolomite & 297.25 & 11.83 \\
\hline Quartz-10 $\boldsymbol{\mu m}$ & 1610.05 & 3.86 \\
\hline Quartz-40 $\boldsymbol{\mu m}$ & 464.56 & 7.42 \\
\hline Quartz-75 $\boldsymbol{\mu m}$ & 270.22 & 17.18 \\
\hline
\end{tabular}

69

Cementitious pastes were prepared using deionized water at a fixed water-to-solid $(\mathrm{w} / \mathrm{s}=0.60$, mass basis) ratio using a planetary mixer as described in ASTM C305 $\left[{ }^{21}\right]$. To better understand the role of fillers, the CAC content was reduced at mass-based replacement levels ranging from 0-to-50\% (mass-basis) by limestone, quartz or dolomite powders. The replacement levels were selected to match the overall area of solids per gram of anhydrous cement across the different fillers used. The additional surface area provided by the fillers was calculated using an area multiplier (AM) proposed by Oey et al. [ $\left.{ }^{7}\right]$ (see Equation 1):

$$
A M=1+\frac{r S S A_{\text {filler }}}{(100-r) S S A_{\text {cement }}}
$$

where, $r$ (mass \%) is percentage of CAC replaced by a filler, $\mathrm{SSA}_{\text {cement }}$ and $\mathrm{SSA}_{\text {filler }}\left(\mathrm{m}^{2} / \mathrm{kg}\right)$ are the specific surface areas of the CAC and filler respectively. The AM parameter accounts for both the dilution effect (i.e., CAC replacement level) and the specific surface area of the solids (i.e., CAC and filler). As such, AM increases with CAC replacement level and filler fineness. Therefore, 
the total area of the solids per gram of anhydrous CAC can be simply calculated as the product of the AM and $\mathrm{SSA}_{\text {cement. }}$ AM serves as a direct measure of additional surface area available for product nucleation. By matching AMs, several mixtures were proportioned with an equivalent surface area of solids per gram of anhydrous $C A C$, i.e., for $A M=1.2,1.5,2.0,3.0$. Figure 2 shows the replacement level required to achieve each AM value for all the fillers used, so long as the CAC replacement level was maintained at $\leq 50 \%$. Table 3 shows the level of CAC replacement required by each filler to ensure the targeted $A M$ values. It should be noted that $A M=3.0$ means that this mixture shows a solid surface area which is $3 x$ larger than the pure CAC mixture (i.e., where $A M=1.0$ ).

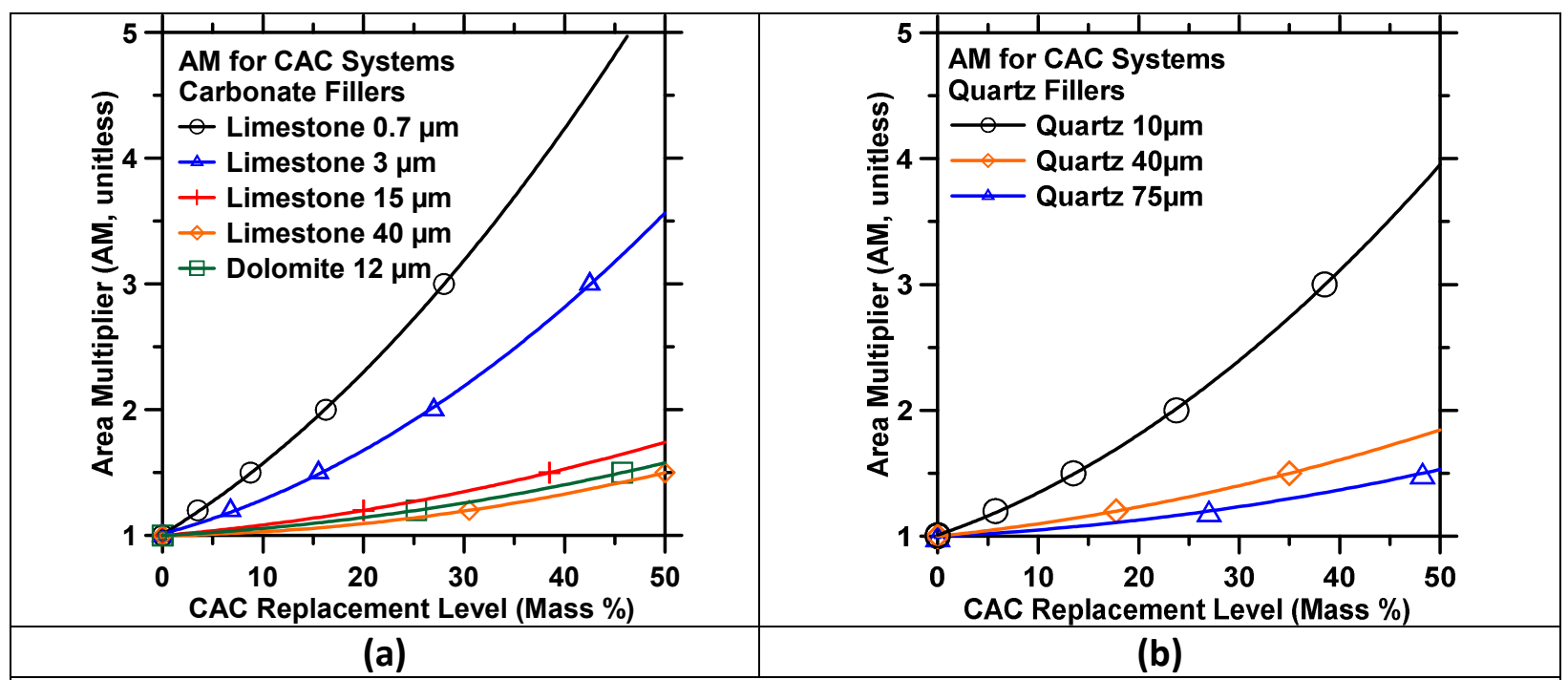

Figure 2: The area multiplier (AM) as a function of level of CAC replacement by: (a) carbonate fillers and (b) quartz fillers. The symbols represent values corresponding to the mixture formulations evaluated in this study.

94 The influence of cement replacement on the rate of CAC reaction was tracked using isothermal 
$25^{\circ} \mathrm{C}$. The rate and extent of heat release are normalized by the mass of CAC and, as such, the heat evolution profiles serve as direct indicators of hydration kinetics of CAC.

Table 3: The level of CAC replacement (\%) calculated for each filler so as to maintain an equivalent value of the area multiplier (AM).

\begin{tabular}{|c|c|c|c|c|}
\hline Filler & AM=1.2 & AM=1.5 & AM=2 & AM=3 \\
\hline Limestone $\mathbf{0 . 7} \boldsymbol{\mu m}$ & 3.50 & 8.75 & 16.25 & $\mathbf{2 8 . 0 0}$ \\
\hline Limestone $\mathbf{3} \boldsymbol{\mu m}$ & 6.75 & 15.50 & 27.00 & 42.50 \\
\hline Limestone $\mathbf{1 5} \boldsymbol{\mu m}$ & 20.00 & 38.50 & $\mathrm{~N} / \mathrm{A}$ & $\mathrm{N} / \mathrm{A}$ \\
\hline Limestone $\mathbf{4 0} \boldsymbol{\mu m}$ & 30.50 & 50.00 & $\mathrm{~N} / \mathrm{A}$ & $\mathrm{N} / \mathrm{A}$ \\
\hline Dolomite & 25.25 & 45.75 & $\mathrm{~N} / \mathrm{A}$ & $\mathrm{N} / \mathrm{A}$ \\
\hline Quartz 75 $\boldsymbol{\mu m}$ & 27.00 & 48.25 & $\mathrm{~N} / \mathrm{A}$ & $\mathrm{N} / \mathrm{A}$ \\
\hline Quartz $\mathbf{4 0} \boldsymbol{\mu m}$ & 17.75 & 35.00 & $\mathrm{~N} / \mathrm{A}$ & $\mathrm{N} / \mathrm{A}$ \\
\hline Quartz $\mathbf{1 0} \boldsymbol{\mu m}$ & 5.75 & 13.50 & 23.75 & 38.50 \\
\hline
\end{tabular}

\subsection{Experimental Results and Discussion}

Due to the use of ambient temperatures and for $\mathrm{w} / \mathrm{c} \geq 0.60$, it is expected that $\mathrm{CAH}_{10}, \mathrm{C}_{2} \mathrm{AH} \mathrm{H}_{8}$ and $\mathrm{AH}_{3}$ hydrates form, and are present in the systems considered herein $\left[{ }^{18}\right]$. Representative $\mathrm{X}$ ray diffraction (XRD) patterns shown in Figure 3 illustrate that at ages less than 2 days, $\mathrm{CAH}_{10}$ and $\mathrm{C}_{2} \mathrm{AH}_{8}$ are the primary hydration products independent of the filler present. In systems prepared without and with fillers, $\mathrm{C}_{2} \mathrm{AH}_{8}$ and $\mathrm{CAH}_{10}$ are the primary hydration products respectively. Formation of $\mathrm{CAH}_{10}$, which is a water-rich hydration product, instead of $\mathrm{C}_{2} \mathrm{AH}_{8}$, at early ages, can be explained due to a higher water-to-cement ratio (w/c) in systems prepared with fillers. It should be noted that due to the very low dissolution rates of limestone and dolomite $\left[{ }^{22}, 23\right]$, substantial reaction between CA and carbonate provided by carbonate based

fillers is not expected $\left[{ }^{24},{ }^{25}\right]$. This is corroborated by the XRD patterns shown in Figure 3(a), wherein the weak intensities of monocarboaluminate indicate its presence in minute 


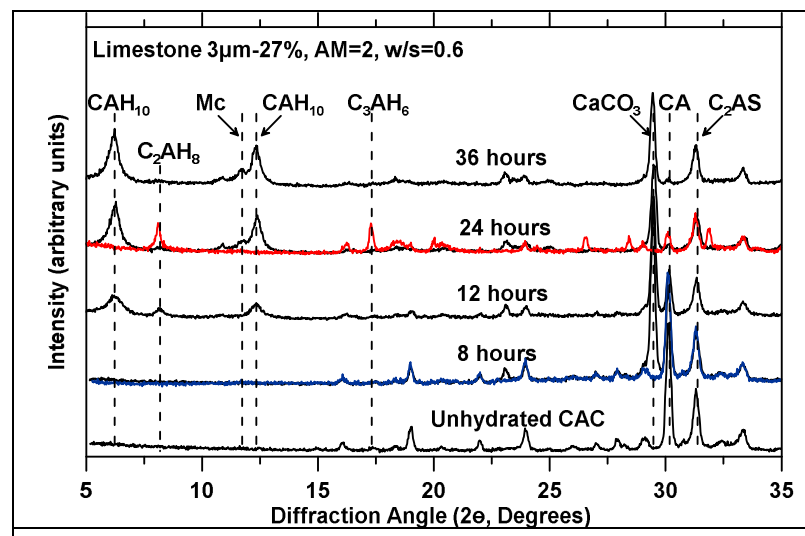

(a)

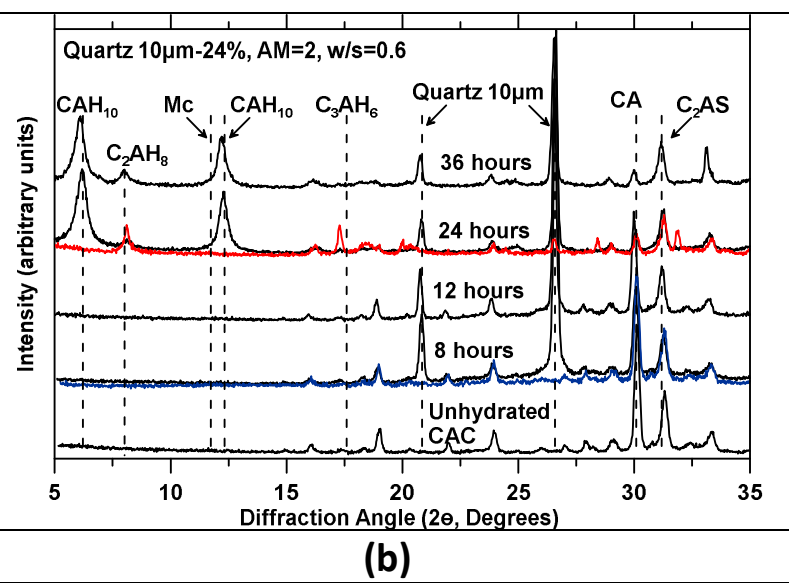

(b)

Figure 3: XRD patterns of CACs pastes prepared at a $w / s=0.60$ for: (a) CAC replacement by limestone at a level of $27 \%$ (by mass) and (b) CAC replacement by quartz at a level of $24 \%$ (by mass). The CAC replacement levels thus selected ensure $A M=2$. The blue and red XRD patterns correspond to pure CAC pastes (no filler) prepared at w/s $=0.60$ at ages of 8 and 24 hours for comparison.

117 Figure 4 shows representative heat evolution profiles for the plain and binary pastes (i.e., CAC + filler) prepared for $A M=1.2,2.0$ and 3.0. The reference system corresponds to a pure CAC (no filler) paste prepared at $\mathrm{w} / \mathrm{s}=\mathrm{w} / \mathrm{c}=0.60$ ( $\mathrm{w}=$ water, $\mathrm{s}=$ solids, $\mathrm{c}=\mathrm{CAC}$, on a mass basis). It is important to clarify that, in this study; w/c refers exclusively to the relation (mass basis) of water to CAC without consideration of the filler. On the other hand, w/s refers to the mass relation of water to all the solids present in the binder (i.e., CAC + filler). In cases where no filler

123 is present $w / c=w / s$. From Figure 4 it is observed that CAC hydration is accelerated in the 124 presence of fillers as compared to the reference system. The enhancement in hydration is 125 noted qualitatively in terms of the increase in the value of the main heat-flow peak. Increasing 126 the filler replacement level induces a shortening of the induction period and left-shift of the 
127 main heat-flow peak (Figure 4a). This is interesting because in mixtures having equivalent AM's

128 (but not CAC replacement), the total solid surface area available for the nucleation of the

129 hydrates is the same, but the effective w/c is different and scales with the replacement level.

130 This relationship between the hydration kinetics and $w / c$ thus, suggests that independent of

131 surface area, a higher w/c leads to enhanced hydration of CAC's. To verify this hypothesis, the

132 hydration kinetics of pure CAC pastes prepared at different w/c were examined (Figure 4d).

133 Indeed, increasing the w/c results in enhanced reactivity. Similar results have been reported by

134 Gosselin et al. $\left[{ }^{26}\right]$ and Siddiqui et al. $\left[{ }^{27}\right]$, wherein enhanced reactivity of CA was attributed to

135 the enhanced growth of the CAC hydrates when additional space is available in the

136 microstructure. It is however postulated that hydration of CAC with increasing w/c is enhanced

137 only up to a limiting w/c value, after which no further enhancement is noted.

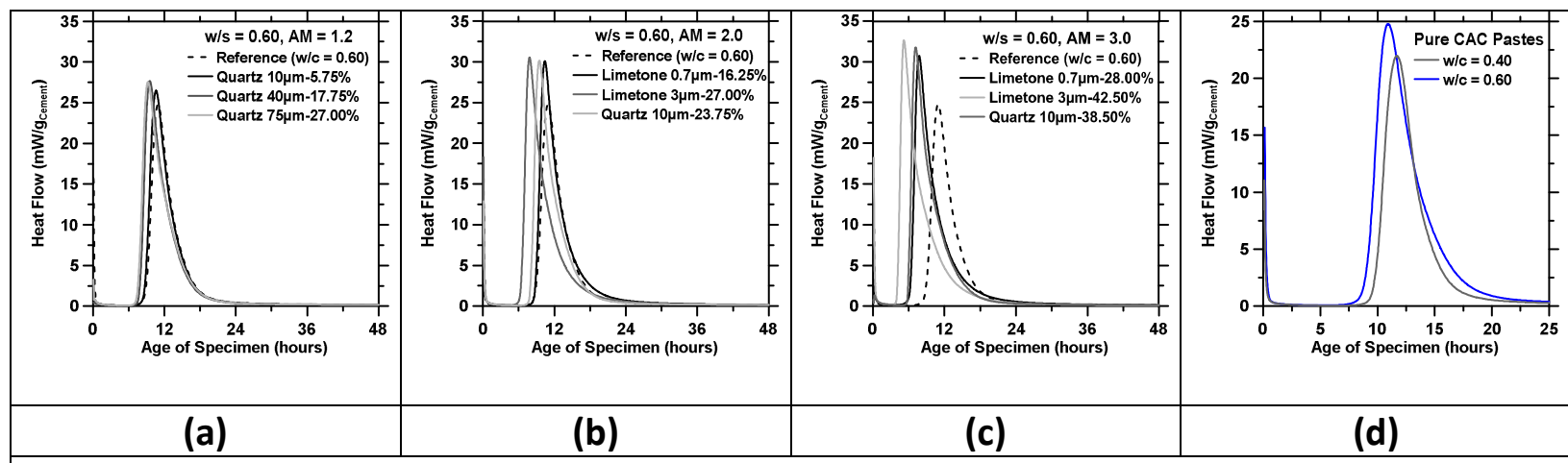

Figure 4: Measured heat evolution profiles for binary paste systems (w/s $=0.60)$ for $(a)$ $A M=1.2$ (b) $A M=2$ and (c) $A M=3$. (d) Heat evolution profiles of CAC pastes prepared at different $w / c$. 


\section{0}

151

152

and thus w/c. Figure 5 shows the heat evolution profiles for systems containing $27 \%$ and $38.5 \%$ of the CAC replaced by limestone and quartz fillers. It is seen that at the same replacement level (i.e., same amount of water available for CAC hydration), the reaction rate enhances with AM on account of a higher surface area being available for product phase nucleation. These results indicate that two factors i.e., surface area availability and water availability both exert controls on the CAC reaction rates.

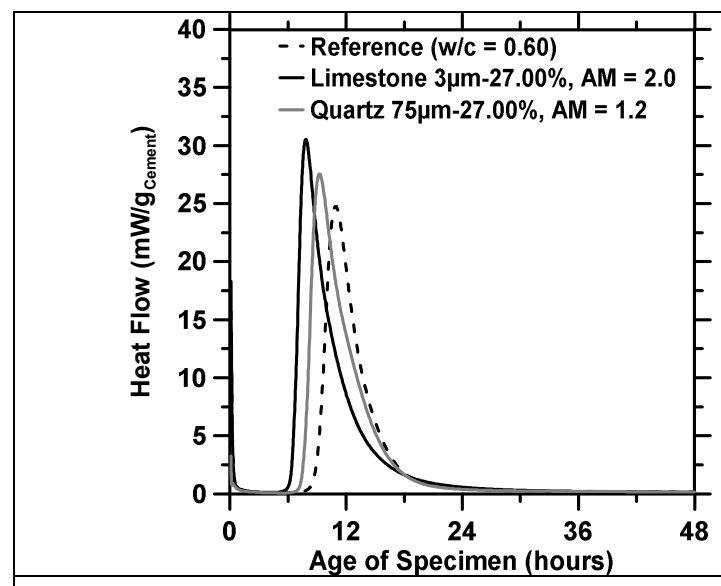

(a)

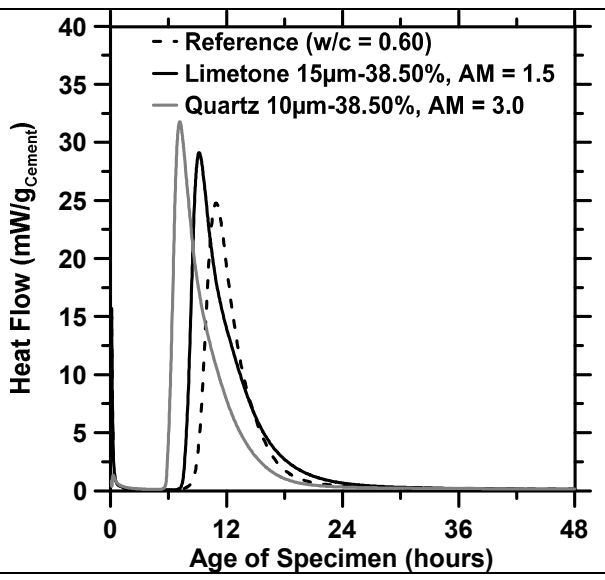

(b)

Figure 5: Heat release curves for CAC mixtures for: (a) $27 \%$ replacement of CAC and (b) $38.5 \%$ replacement of CAC, by limestone and quartz fillers. The reference designates a cementitious blend containing no filler agents, i.e., pure CAC for $w / s=0.60$.

While discussing water availability it should be pointed out that some of the filler containing mixtures considered herein, showed a tendency to bleed. It is important to quantify the content of such bleed water as if the mixture is to set with bleed water on the surface, this water is not uniformly available to partake in hydration - and should be discounted from consideration $\left[{ }^{28}\right]$. The consolidation of the paste in the vertical direction during the plastic state also alters the packing of particles - resulting in a reduction in the solid-solid separations in the material. To better quantify bleeding effects, the bleed water exhausted to the sample surface was removed 
in Figure 6).

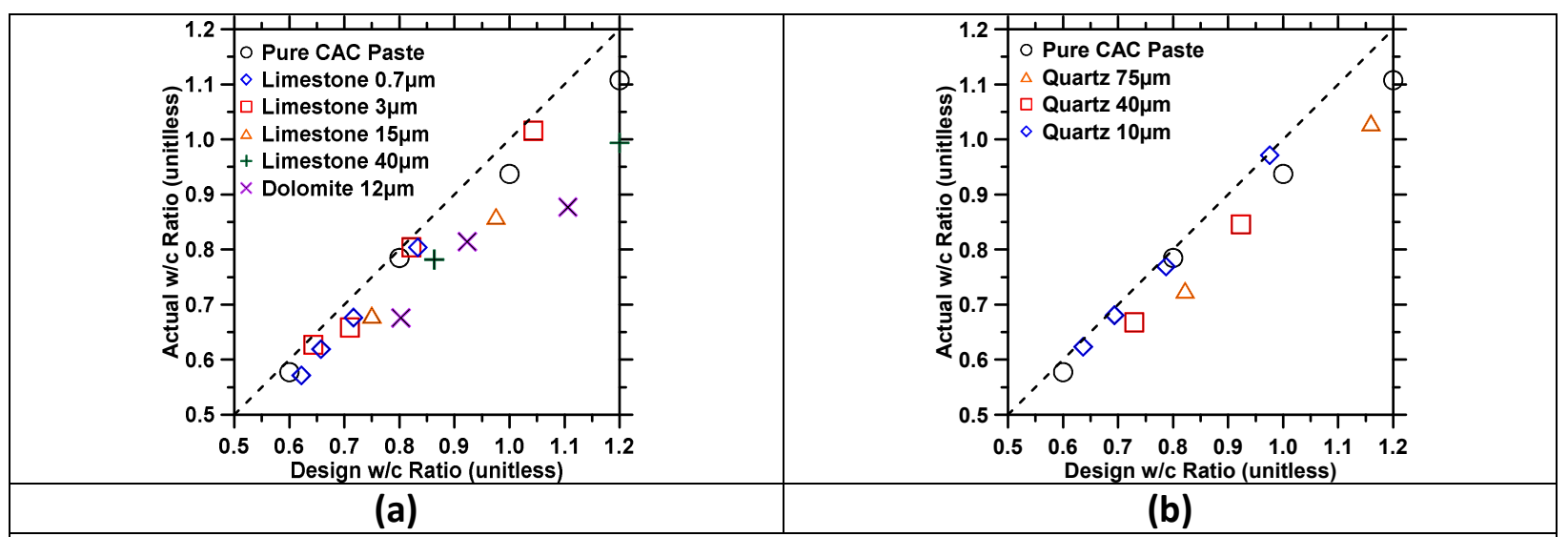

Figure 6: The actual w/c of the mixtures determined by correcting for the effects of bleeding,

as a function of the design $w / c$ for: (a) carbonate fillers and b) quartz fillers.

and its mass determined for all mixtures considered herein, over the first 8 hours of hydration.

This data was used to quantify the actual $w / s$ and $w / c$ for each mixture to understand any possible impact on CAC hydration rates. Expectedly, the high w/c systems (i.e., those containing a higher quantity of mineral filler) expel more water; an effect which exacerbates as the filler particle size increases (i.e., when filler particles coarser than the CAC are introduced; as shown
164

The heat evolution profiles presented in Figures (3-5) were processed to extract calorimetric parameters indicative of CAC hydration kinetics including: (a) slope during acceleration regime, (b) inverse of time elapsed from initial water contact to the main heat peak, and (c) amplitude of the heat peak (i.e., the heat flow value at the main peak). These quantities were analyzed in the context of the actual $\mathrm{w} / \mathrm{c}$ and the surface area of the solids, presented in the form of the AM. Figure 7 shows the calorimetric parameters as function of the actual $w / c$ for each mixture. It is seen that as w/c increases, CAC hydration is enhanced, as indicated by the broadly linear correlation between the calorimetric parameters and w/c. It is also noted that at equal w/c, the acceleration induced by all fillers is comparable to each other. 


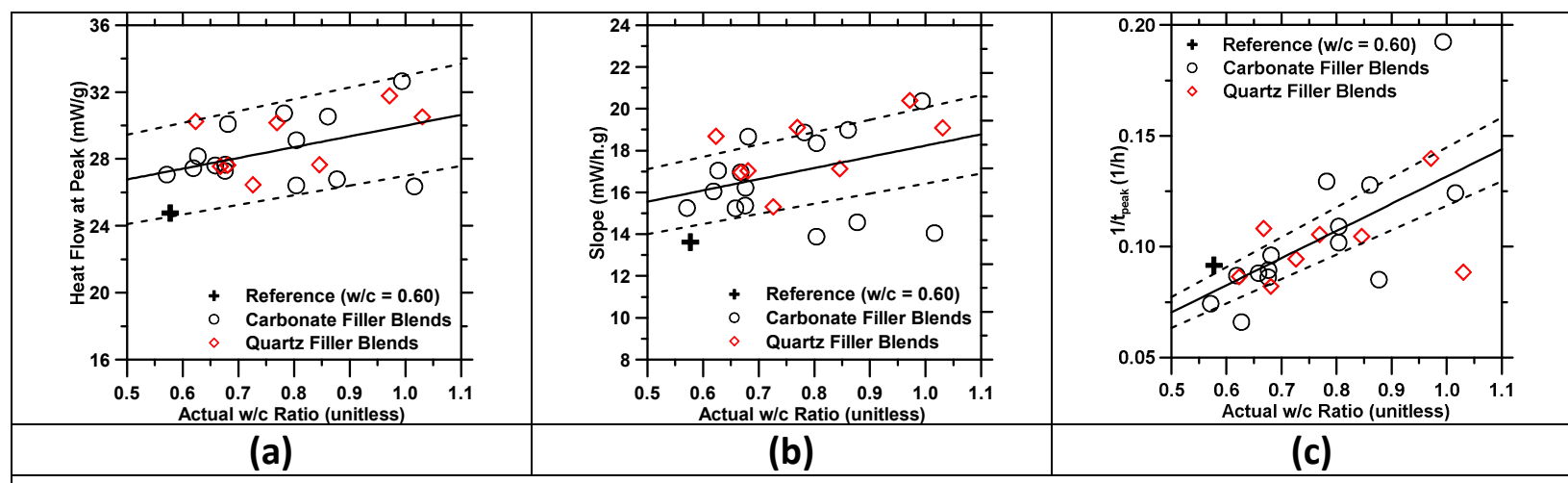

Figure 7: The correlation between the calorimetric parameters and the actual w/c (determined by discounting water loss due to bleeding) for: (a) heat flow at peak, (b) slope in the acceleration regime, (c) inverse of time to main peak. The solid lines show a best fit line to the dataset while the dashed lines represent $\mathrm{a} \pm 10 \%$ bound to the best fit line.

175

176

177

178

179

180

181

182

183

184

185

186

In addition to water availability, the amount of surface area available and its relation to CAC hydration kinetics was also examined (Figure 8). CAC hydration is enhanced as the amount of surface area provided by the fillers increases. It is noted that all three fillers: quartz, limestone and dolomite, enhance hydration of CAC equivalently - a significant conclusions which indicates that all fillers, at equivalent surface areas, contribute equally towards enhancing CAC hydration. In light of results shown in Figure (7-8), it is postulated that in CAC binders both carbonaceous and quartz fillers have equivalent acceleratory effects because: (a) the primary hydrates formed in CAC systems are not sensitive to the uptake of carbonate ions and (b) neither of these fillers provide a desired surface (i.e., more desired than the CAC grains themselves) for the nucleation of the CAC hydrates. It should be noted that the scatter in the datasets presented in Figures (78) can be attributed to: (a) bleeding, which cannot be remediated during isothermal calorimetry measurements and (b) differences in surface morphologies of the fillers, which may contribute to some differences in reaction rates. The morphologies of the filler can indeed have an impact 
189 in the density of product nuclei that form on the surface of the fillers. Some of the morphological features that can vary amongst the fillers are distribution of defects, etc. Such

191

192

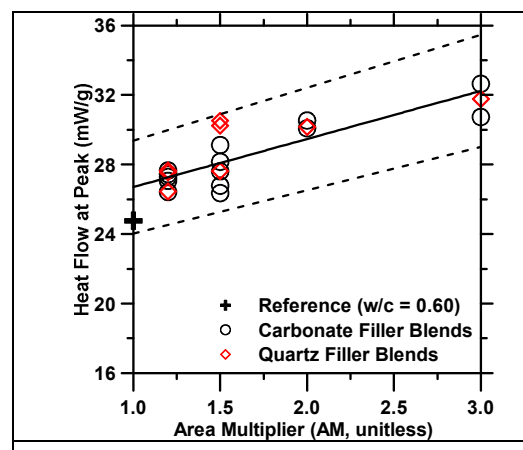

(a)

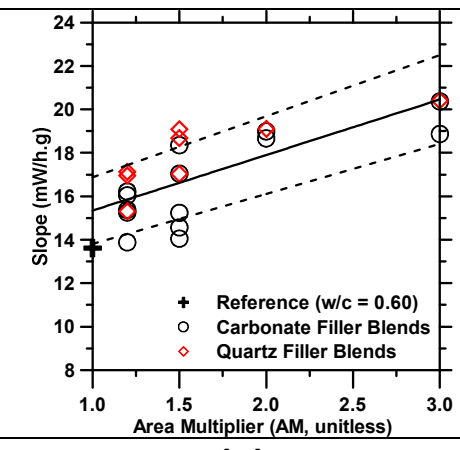

(b)

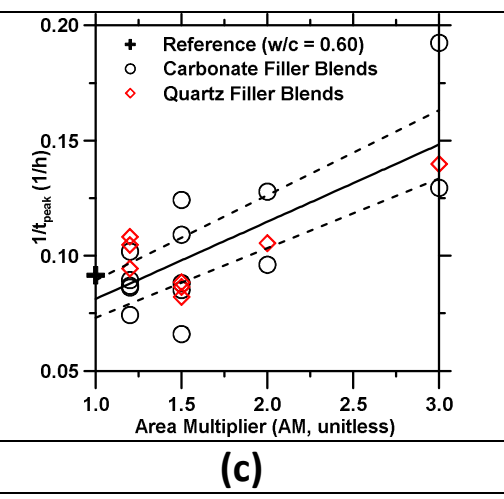

(c)

Figure 8: The correlation between the area multiplier (AM) and: (a) heat flow at peak, (b) slope of the acceleration regime, (c) inverse of time to main peak. The solid lines show a best fit line to the data set while the dashed lines represent $a \pm 10 \%$ bound to the best fit line.

\subsection{Numerical Simulations of the Heat Release Response}

The hydration of OPC's and pure cement phases has widely been studied using phase boundary

nucleation and growth (BNG) models $\left[{ }^{29}, 30,31,32,33,34\right]$. These models simulate the nucleation and growth of a single product phase that starts at the solid phase boundaries. However, these models can incorporate different assumptions about the nucleation process (i.e., homogeneous or heterogeneous), frequency of nucleation (i.e., site saturation or continuous nucleation) and mechanisms of product growth (i.e., isotropic or anisotropic growth of product). Due to their 
204 flexibility, BNG models have been successfully extended to study the effects of various process 205 parameters including addition of chemical admixtures $\left[{ }^{35}, 36\right.$ and mineral filler additions $\left[{ }^{7},{ }^{11}\right]$.

207 Few studies have applied BNG models to describe hydration of CAC-based systems. Ukrainczyk $208\left[{ }^{37}\right]$ applied a combination of three different mechanisms: i.e., nucleation and growth, chemical 209 interaction and mass transfer to simulate CAC hydration. This study applies a modified BNG 210 formulation, described previously to describe the influences of different fillers on the kinetics of 211 reactions in CAC based systems $[7,11,29,32,35,38,39]$. A filler is assumed to accelerate CAC reactions, 212 the extent of which is calculated from Eq. (2), by providing only additional surface area for 213 product nucleation, without any impacts on the nature of the CAC hydration products, in terms 214 of their properties or composition, i.e., the filler is assumed to be inert (see Figure 3).

$$
\text { Extent of Transformation }(X)=1-\exp \left[-2 \mathrm{a}_{\mathrm{BV}} \int_{0}^{\mathrm{G}_{\text {out }} \mathrm{t}}\left(1-\exp \left(-\mathrm{A}_{\mathrm{f}}\right)\right) \mathrm{dy}\right]
$$

215 where: $\mathrm{X}$ is the volume fraction of the reactant transformed to product, $\mathrm{G}_{\text {out }}$ is the isotropic 216 outward growth rate of the product phase, $y$ is a variable of integration, $a_{B V}$ is the boundary 217 area per unit volume, $t$ is the simulation time $(h)$ and $A_{f}$ is the extended area of the transformed 218 product phase described in Equations (3-4).

$$
\begin{gathered}
A_{f}=\pi\left[I_{\text {density }} \cdot G_{\text {par }}^{2} \cdot\left(t_{r}^{2}-\frac{y^{2}}{G_{\text {out }}^{2}}\right)+I_{\text {rate }} \cdot G_{\text {par }}^{2} \cdot\left(\frac{t_{r}^{3}}{3}-\frac{y^{2} t_{r}}{G_{\text {out }}^{2}}+\frac{2 y^{3}}{3 G_{\text {out }}^{3}}\right)\right] \text { if }(y \\
\geq G_{\text {out }} \cdot t_{r} \\
\text { and, } A_{f}=0 \text { if }\left(y<G_{\text {out }} \cdot t_{r}\right) \\
\text { Here }\left(t_{r}=\left(t-t_{0}\right)\right)
\end{gathered}
$$


220 The model formulation is discussed in detail elsewhere $\left[{ }^{7},{ }^{11},{ }^{35}\right]$. The parameters used in the

221 model include: (a) $I_{\text {density }}\left(\mu \mathrm{m}^{-2}\right)$, the nucleation density of the product, that is, the number of

222 supercritical nuclei per unit surface area formed at the time of nucleation event $\left(t_{0)},(b) I_{\text {rate }}\right.$

$223\left(\mu \mathrm{m}^{-2} \cdot \mathrm{h}^{-1}\right)$, the nucleation rate, $(\mathrm{c}) \mathrm{G}_{\mathrm{par}}\left(\mu \mathrm{m} . \mathrm{h}^{-1}\right)$, the growth rate parallel to the particle surface,

224 (d) $G_{\text {out }}\left(\mu \mathrm{m} . \mathrm{h}^{-1}\right)$, the outward growth rate perpendicular to the particle surface and $(e) a_{f}$

225 (unitless), the simulation analogue of the area multiplier (AM) which represents in the increase

226 the in solid surface area provided by fine fillers. The w/s, specific surface area of the CAC and

227 the fillers $\left(\mathrm{SSA}_{\text {cement }}\right.$ and $\left.\mathrm{SSA}_{\text {filler }}\right)$ and CAC replacement level $(r, \%)$ are used as inputs. The

228 cumulative heat evolved by the reaction of the CAC is computed using a scaling parameter, A

$229(\mathrm{~kJ} / \mathrm{mole})$, as shown in Equation (5):

230

$$
\text { Rate of heat evolution }=\frac{d H}{d t}=A \cdot\left(\frac{100}{100-r}\right) \frac{d X}{d t}
$$

231

232 where: $\mathrm{X}$ is the volume fraction of reactant transformed to product, $r(\%)$ is the mass-based 233 percentage replacement level of mineral filler (when present) which accounts for the effects of 234 dilution (i.e., a reduction in the CAC content). In addition, since the simulations begin only at 235 the end of the induction period which varies slightly from one mixture to the another, the 236 simulation time is mapped to real time by using a parameter $t_{0}$ (hours).

238 For all simulations, $I_{\text {rate, }} G_{\text {out }}$ and $G_{\text {par }}$ are fixed; taking values of $0.00 \mu \mathrm{m}^{-2} \cdot \mathrm{h}^{-1}, 0.054 \mu \mathrm{m} \cdot \mathrm{h}^{-1}$ and $2390.027 \mu \mathrm{m} \cdot \mathrm{h}^{-1}$ respectively. The $2: 1$ ratio of the outward product growth rate with respect to the parallel one is representative of dendritic growth of the product $\left[{ }^{40}\right]$. Since, the growth rates of 
241 the hydration products in CAC systems have not been measured, the value of the outward

242 growth rate is drawn from simulations of other cementitious systems [ $\left.{ }^{7}\right]$. It is pointed out that

243 the assignment of $I_{\text {rate }}=0.00 \mu \mathrm{m}^{-2} \cdot \mathrm{h}^{-1}$ corresponds to nucleation site-saturation, implying that

244 growth of the product phases begins from nuclei that are initially present, or form at very early

245 ages, and no further nuclei are permitted to form after the initial nucleation burst. To fit the

246 reaction response of the mixtures, a simplex algorithm was applied, which iteratively varies the

247 values of the $I_{\text {density, }} a_{\text {factor, }} A$ and $t_{0}$, within pre-defined constraints, to minimize the difference

248 between the simulated and measured heat evolution profiles $\left[{ }^{7}\right]$.

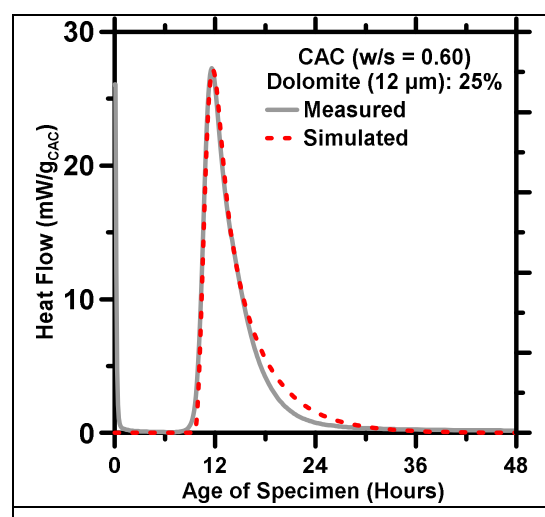

(a)

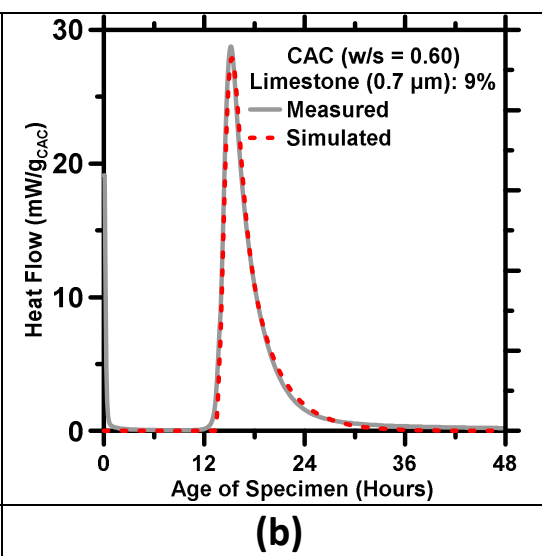

(b)

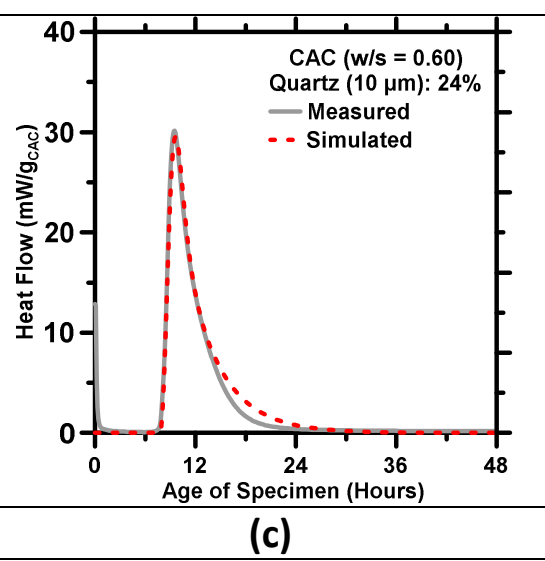

(c)

Figure 9: A comparison of representative measured versus BNG simulated heat evolution profiles for a range of CAC mixtures. The \% value denotes the mass-based replacement level of the CAC by a mineral filler.

251 When the simplex algorithm converges, the values of the fitting parameters are extracted and

252 noted as the optimum values. Amongst the variable parameters, $a_{f}$ and $I_{\text {density, }}$ are most critical

253 as they can be combined with SSA $_{\text {cement }}$ to calculate the number of supercritical product nuclei

254 produced per gram of CAC as shown in Equation (6). 


\section{Product Nuclei(\#/ $\left.g_{c}\right)=\left(S S A_{c} \cdot a_{f}\right) \cdot I_{\text {density }}$}

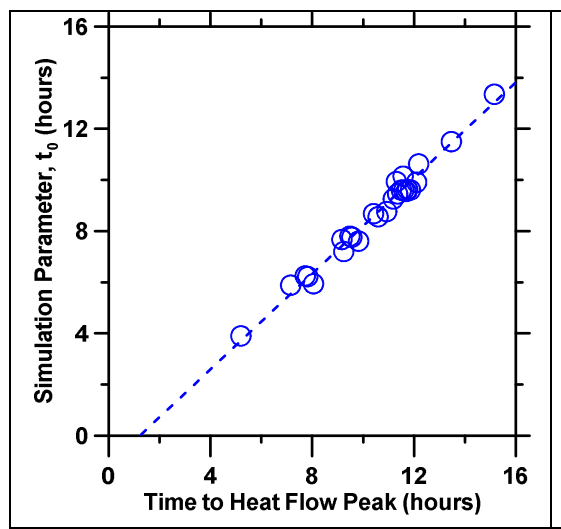

(a)

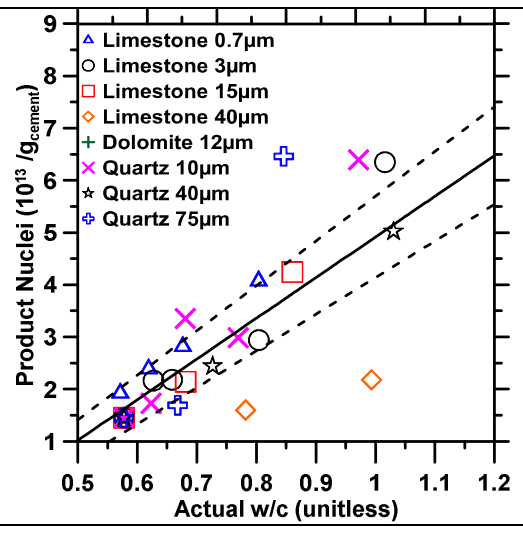

(b)

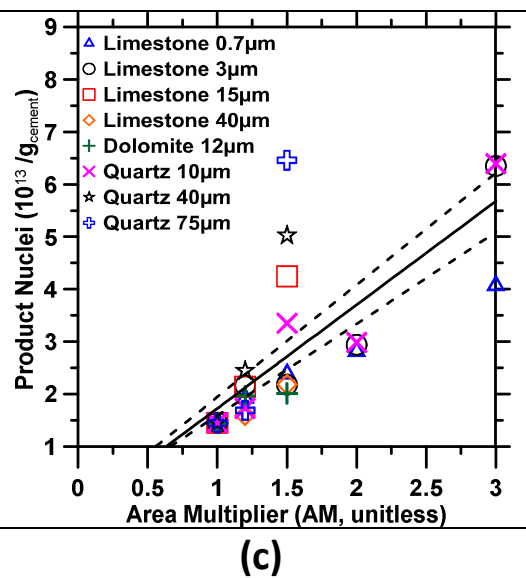

(c)

Figure 10: (a) A comparison of the simulation parameter, $t_{0}$ as a function of $t_{\text {peak }}$ (time to the main peak) extracted from measured heat profiles across all systems. Product nuclei formed per gram of CAC as a function of: (b) the actual w/c and (c) area multiplier (AM). The solid line indicates best fits and the dashed lines indicate $\pm 10 \%$ bounds.

Figure 9 shows representative heat evolution profiles obtained via BNG simulations, compared systems containing different fillers and CAC replacement levels. Excellent agreement is noted are low. The values of the supercritical product nuclei formed at the end of the induction period were examined. As seen in Figure 10(b), with increasing w/c, the number of the product nuclei 
This increase in the number of product nuclei is also noted with an increase in the AM (Figure

271 10c), suggesting that the availability of water and surface are both important contributors to

272 CAC reaction rates. It is uniformly noted, no preference to a given filler is seen, with all fillers

273 provided the same acceleration in CAC hydration - for equivalent AM, and w/c.

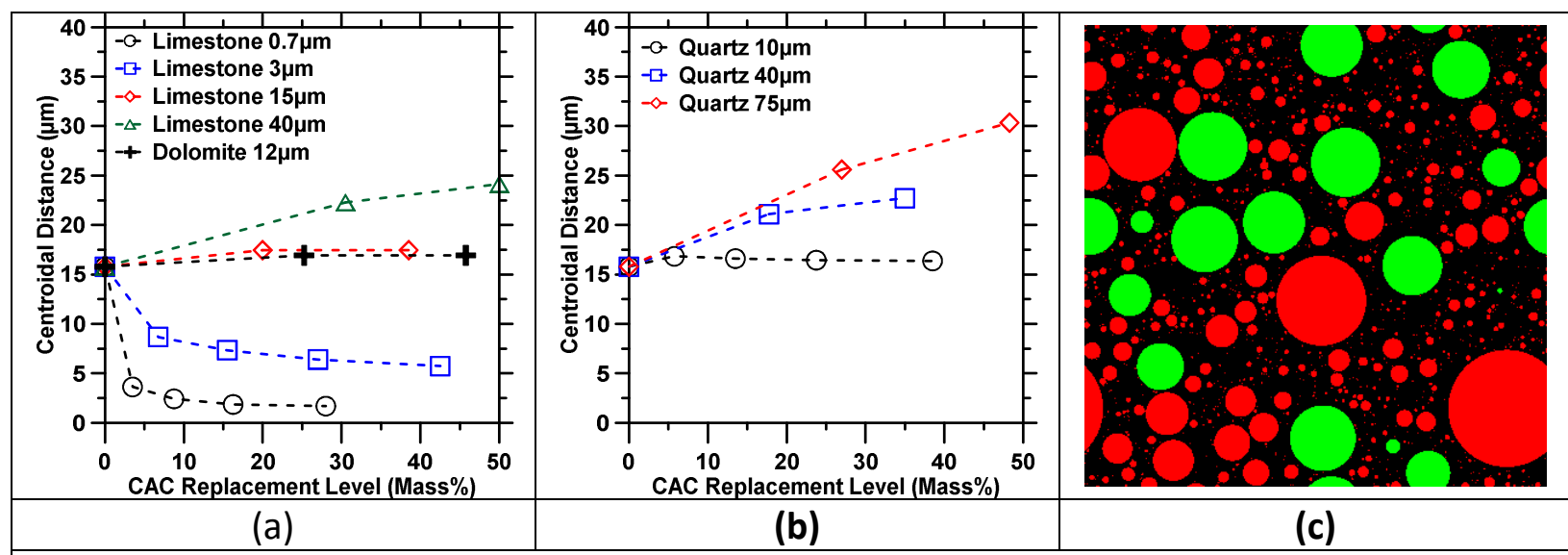

Figure 11: The average centroidal solid-to-solid distance calculated for various CAC systems prepared at a w/s $=0.60$ with CAC replaced by: (a) carbonate and (b) quartz fillers at replacement levels ranging from 0 to $50 \%$ (by mass). The distances are calculated by averaging the distances between the center of a particle with respect to its nearest neighbors, packed within a three-dimensional virtual cube for an edge length (of the cube) of $1000 \mu \mathrm{m}$. (c) A 2D slice of a 3D-microstructure for a system prepared at w/s $=0.60$ with $10 \%$ of the CAC (red spheres) replaced by dolomite (green).

277 water calculated using a microstructural model $\left[{ }^{9}\right]$, for all three mineral fillers across different CAC replacement levels. It is seen that fillers which are finer than CAC, cause a progressive decrease in the inter-particle distance with increasing replacement levels. On the other hand, coarser fillers cause an increase in the inter-particle distance, more so as the replacement level of CAC by a coarse filler increases. It is seen that at the same replacement level, (i.e., equivalent w/c) the quartz, limestone and dolomite filler produce widely different inter-particle distances 
283 on account of differences in their particle size distributions. However, as shown in Figure 10(b),

284 at the same w/c, all three fillers enhance hydration of CAC similarly. These trends show that the

285 enhancement in CAC hydration depends on the effective w/c, i.e., a measure of the total space

286 available in the microstructure per unit mass of cement, but not necessarily the inter-particle

287 (i.e., solid to solid) distance so long the amount of available surface area remains consistent.

289 Figure 10 (c) shows that the number of product nuclei, formed at the end of the induction 290 period, is linearly proportional to additional surface area provided by the fillers. This suggests 291 that CAC hydrated is enhanced by the provision of additional solid surface area for the 292 heterogeneous nucleation of products. For equivalent (incremental) surface areas provided by 293 the different fillers, the enhancement in CAC hydration remains broadly similar. This supports 294 the idea that all three filler types used in this study promote the nucleation of products onto 295 their surfaces equivalently, and rules out the possibility of the carbonaceous fillers participating 296 in any substantial chemical interaction with the anhydrous or product phases present in CAC 297 systems, especially so at early ages (i.e., less than 7 days, see Figure 3).

\section{$299 \quad$ 5.0. Summary and Conclusions}

300 The hydration kinetics of CAC-based mixtures has been examined in the presence of both 301 carbonate (i.e., limestone and dolomite) and quartz fillers. By using the concept of an area 302 multiplier (AM), the increased surface area provided by the fillers has been correlated with 303 noted increases in CAC reaction rates. In addition to surface area, CAC reaction rates are also 304 dependent on w/c, i.e., the amount of space available in the microstructure. Unlike the case of 
305 OPC, CAC's show no preference for filler chemistry, or type - as such, for an equivalent increase 306 in surface area, all fillers provide equivalent enhancements in reaction rates. This equivalence 307 in acceleratory effects amongst the three fillers examined herein is attributed to: (a) their inert 308 nature, i.e., their inability to partake in chemical reactions with the CAC, especially at early ages 309 and for the temperatures considered, and, (b) equivalent affinity for heterogeneous nucleation 310 of hydration products onto their surfaces. These conclusions are supported by the outcomes of 311 phase boundary nucleation and growth modeling applied to CAC hydration. It is also shown that

312 the enhancement in hydration of CACs is related to the increase in w/c (i.e., dilution effects) but 313 not necessarily the inter-particle distance between the solid particles at the time of mixing.

\section{$315 \quad 6.0$ Acknowledgements}

316 The authors acknowledge full financial support for this research provisioned by the University 317 of California, Los Angeles (UCLA) and the National Science Foundation (CMMI: 1066583). The 318 authors acknowledge the provision of materials by OMYA A.G., Kerneos Aluminates and U.S. 319 Silica. The contents of this paper reflect the views/opinions of the authors, who are responsible 320 for the accuracy of the data presented herein. This research was conducted in the Laboratory 321 for the Chemistry of Construction Materials $\left(\right.$ LC $\left.^{2}\right)$ and Molecular Instrumentation Center (MIC) 322 at the University of California, Los Angeles (UCLA). As such, the authors gratefully acknowledge 323 the support that has made these laboratories and their operations possible. 
$\left.{ }^{1}\right]$ Concrete for the Environment. Published on Behalf of the Nordic Network Concrete for Environment by SP Swedish National Testing and Research Institute, Boras, Sweden, June 2003. [2] Worrell E, Price L, Martin N, Hendriks C, Ozawa Meida L. Carbon dioxide emissions from the global cement industry 1. Annu. Rev. Energy Environ. 2001; 26: 303-329.

[3] Hendriks CA, Worrell E, De Jager D, Blok K, Riemer P. Emission reduction of greenhouse gases from the cement industry. Proceedings of the Fourth International Conference on Greenhouse Gas Control Technologies 1998; 939-944.

$\left[{ }^{4}\right]$ Gutteridge W, Dalziel J. Filler cement: the effect of the secondary component on the hydration of Portland cement: part I. A fine non-hydraulic filler. Cem. Concr. Res. 1990; 20: 778782.

[5] Gutteridge W, Dalziel J. Filler cement: The effect of the secondary component on the hydration of Portland cement: Part 2: Fine hydraulic binders. Cem. Concr. Res. 1990; 20: 853861.

$\left[{ }^{6}\right]$ Lothenbach B, Scrivener K, Hooton RD. Supplementary cementitious materials. Cem. Concr. Res. 2011; 41: 1244-1256.

[7] Oey T, Kumar A, Bullard JW, Neithalath N, Sant G. The filler effect: the influence of filler content and surface area on cementitious reaction rates. J. Am. Ceram. Soc. 2013; 96: 19781990.

$\left.{ }^{8}\right]$ Martin C, Lawrence P, Ringot E. Efficiency of mineral admixtures in mortars: quantification of the physical and chemical effects of fine admixtures in relation with compressive strength. Cem. Concr. Res. 2006; 36: 264-277.

$\left[{ }^{9}\right]$ Kumar A, Oey T, Kim S, Thomas D, Badran S, Li J, Fernandes F, Neithalath N, Sant G. Simple methods to estimate the influence of limestone fillers on reaction and property evolution in cementitious materials. Cem. Concr. Comp. 2013;42: 20-29.

$\left[{ }^{10}\right]$ Vance K, Aguayo M, Oey T, Sant G, Neithalath N. Hydration and strength development in ternary portland cement blends containing limestone and fly ash or metakaolin. Cem. Concr. Comp. 2013; 39: 93-103.

${ }^{[11}$ ] Kumar A, Oey T, Puerta-Falla G, Henkensiefken R, Neithalath N, Sant G. A comparison of intergrinding and blending limestone on reaction and strength evolution in cementitious materials. Constr. Build. Mater. 2013; 43: 428-435.

$\left.{ }^{[12}\right]$ Lothenbach B, Le Saout G, Gallucci E, Scrivener K. Influence of limestone on the hydration of Portland cements. Cem. Concr. Res. 2008; 38: 848-860.

$\left[{ }^{13}\right]$ Matschei T, Lothenbach B, Glasser FP. The AFm phase in Portland cement. Cem. Concr. Res. 2007; 37: 118-130.

$\left[{ }^{14}\right]$ Maciej Z, Bremseth SK, Whitehead M, Haha MB. Effect of CaMg $\left(\mathrm{CO}_{3}\right)_{2}$ on hydrate assemblages and mechanical properties of hydrated cement pastes at $40^{\circ} \mathrm{C}$ and $60^{\circ} \mathrm{C}$. Cem. Concr. Res. 2014; 65: 21-29. 
$\left.{ }^{15}\right]$ Kumar A, Sant G, Patapy C, Gianocca C, Scrivener K. The influence of sodium and potassium hydroxide on alite hydration: Experiments and simulations. Cem. Concr. Res. 2012; 42: 15131523.

$\left.{ }^{16}\right]$ Scrivener K, Capmas A, Calcium aluminate cements, Chapter 13, in: P.C. Hewlett (Ed.), Lea's Chemistry of Cement and Concrete, John Wiley \& Sons, New York, 1998.

$\left[{ }^{17}\right]$ Lothenbach B, Pelletier-Chaignat L, Winnefeld F. Stability in the system $\mathrm{CaO}-\mathrm{Al}_{2} \mathrm{O}_{3}-\mathrm{H}_{2} \mathrm{O}$. Cem. Concr. Res. 2012; 42: 1621-1634.

$\left.{ }^{[18}\right]$ Scrivener K, Cabiron J, Letourneux R. High-performance concretes from calcium aluminate cements. Cem. Concr. Res. 1999; 29: 1215-1223.

$\left[{ }^{19}\right]$ Falzone G, Balonis M, Sant G. X-AFm stabilization as a mechanism of bypassing conversion phenomena in calcium aluminate cements. Cem. Concr. Res. 2015; 72: 54-68.

$\left[{ }^{20}\right]$ Garboczi E, Bullard JW. Shape analysis of a reference cement. Cem Concr Res 2004; 34: 1933-1937.

$\left.{ }^{21}\right]$ ASTM. "Annual book of ASTM standards." West Conshohocken, PA: ASTM, 2010.

$\left.{ }^{22}\right]$ Kumar A, Reed J., Sant G. Vertical Scanning Interferometry: A New Method to Measure the Dissolution Dynamics of Cementitious Minerals. J. Am. Ceram. Soc. 2013; 96: 2766-2778.

$\left[{ }^{23}\right]$ Luttge A, Winkler $U$, Lasaga AC. Interferometric study of the dolomite dissolution: a new conceptual model for mineral dissolution. Geochim. Cosmochim. Acta 2013; 67: 1099-1116.

$\left[{ }^{24}\right]$ Luz AP, Pandolfelli VC. $\mathrm{CaCO}_{3}$ addition effect on the hydration and mechanical strength evolution of calcium aluminate cement for endodontic applications. Ceram. Inter. 2012; 38: 1417-1425.

[ $\left.{ }^{25}\right]$ Mindess S, Diamond S. SEM investigations of fracture surfaces using stereo pairs: II. Fracture surfaces of rock-cement paste composite specimens. Cem. Concr. Res. 1992; 22: 678688.

$\left[{ }^{26}\right]$ Gosselin C, Gallucci E, Scrivener K. Influence of self heating and Li 2 SO 4 addition on the microstructural development of calcium aluminate cement. Cem. Concr. Res. 2010; 40: 15551570.

$\left[{ }^{27}\right]$ Siddiqui MS, Nyberg W, Smith W, Blackwell B, Riding KR. Effect of curing water availability and composition on cement hydration. ACI Mat. J. 2013; 110: 315-322.

$\left[{ }^{28}\right]$ Yim HJ, Kim JH, Han HH, Kwak H. Influence of Portland cement and ground-granulated blastfurnace slag on bleeding of fresh mix. Const. Build. Mater. 2015; 80: 132-140.

$\left[{ }^{29}\right]$ Thomas JJ. A new approach to modeling the nucleation and growth kinetics of tricalcium silicate hydration. J. Am. Ceram. Soc. 2007; 90: 3282-3288.

$\left.{ }^{[30}\right]$ Thomas JJ, Jennings HM, Chen JJ. Influence of nucleation seeding on the hydration mechanisms of tricalcium silicate and cement. J. Phys. Chem. C 2009; 113: 4327-4334.

${ }^{31}$ ] Scherer GW, Zhang J, Thomas JJ. Nucleation and growth models for hydration of cement. Cem. Concr. Res. 2012; 42: 982-993. 
$\left.{ }^{32}\right]$ Peterson VK, Whitten AE. Hydration processes in tricalcium silicate: application of the boundary nucleation model to quasielastic neutron scattering data. J. Phys. Chem. C 2009; 113: 2347-2351.

$\left[{ }^{33}\right.$ ] Garrault S, Finot E, Lesniewska E, Nonat A. Study of CSH growth on C3S surface during its early hydration. Mater. Struc. 2005; 38: 435-442.

$\left[{ }^{34}\right]$ Kumar A, Bishnoi S, Scrivener KL. Modelling early age hydration kinetics of alite. Cem. Concr. Res. 2012; 42: 903-918.

$\left[{ }^{35}\right.$ ] Oey T, Stoian J, Li J, Vong, C, Balonis M, Kumar A, Franke W, Sant G. Comparison of Ca( $\left(\mathrm{NO}_{3}\right)_{2}$ and $\mathrm{CaCl}_{2}$ Admixtures on Reaction, Setting, and Strength Evolutions in Plain and Blended Cementing Formulations. J. Mater. Civ. Eng. 2014; 04014267-1 04014267-12

$\left[{ }^{36}\right]$ Kumar A, Sant G, Patapy C, Gianocca C, Scrivener K. The influence of sodium and potassium hydroxide on alite hydration: Experiments and simulations. Cem. Concr. Res. 2012; 42; 15131523.

$\left[{ }^{37}\right]$ Ukrainczyk, N. Kinetic modeling of calcium aluminate cement hydration. Chem. Eng. Sci. 2010; 65: 5605-5614.

[ $\left.{ }^{38}\right]$ Garrault, S, Nonat, A. Hydrated layer formation on tricalcium and dicalcium silicate surfaces: experimental study and numerical simulations. Langmuir 2001; 17: 8131-8138.

$\left.{ }^{39}\right]$ Cahn, J, W. The kinetics of grain boundary nucleated reactions. Act. Metal. 1956; 4: 449459.

$\left[{ }^{40}\right]$ Scherer, George W. Models of confined growth. Cem. Concr. Res. 2012; 42: 1252-1260. 